\title{
RURAL MODEL OF INDUSTRIAL DEVELOPMENT IN JAUNPUR DISTRICT AND PLANNING FOR INTEGRATED RURAL DEVELOPMENT
}

\section{जौनपुर जनपद में औद्योगिक विकास का ग्राम्य प्रतिरूप तथा समन्वित ग्राम्य विकास हेतु नियोजन}

\author{
Dr. Anamika Singh ${ }^{1} \bowtie$, Sujita Devi ${ }^{2}$ \\ ${ }^{1}$ Associate Professor, Raja Srikrishna Dutt P.G., College Jaunpur Uttar Pradesh, India \\ 2 M.A. (Geography), Geography Department, Raja Srikrishna Dutt P.G., College Jaunpur Uttar \\ Pradesh, India
}

DOI: https://doi.org/10.29121/granthaalayah.v8.i12.2020.2705

Article Type: Research Article

Article Citation: Dr. Anamika Singh, and Sujita Devi. (2020). RURAL MODEL OF INDUSTRIAL DEVELOPMENT IN JAUNPUR DISTRICT AND PLANNING FOR INTEGRATED RURAL DEVELOPMENT. International Journal of Research -GRANTHAALAYAH, 8(12), 195-200. https://doi.org/10.29121/granthaalayah.v8.i12.2020.2705

Received Date: 07 December 2020

Accepted Date: 31 December 2020

\section{ABSTRACT}

English: The research study area presented is "Rural Development Dynamics in Jaunpur District: A Geographical Study" under the rural model of industrial development and planning for integrated rural development. At present, rural agriculture, rural industry, business employment are the resources of rural development for social, economic, political development in the Indian rural area. India is a country of villages, so for the development of the villages, there is an urgent need for coordinated planning of small and cottage industrial development for rural development. "The glorious point of Jaunpur district from the past is in front of us on the peak of the Sultanate. According to historian Afrikan is not true. Jaunpur city was inhabited since ancient times and had the distinction of being the capital of an ancient Hindu kingdom. [1]The ancient city of Jaunpur was named Javanpur. Ferozeshah Tughlaq laid the foundation of Jaunpur city on the banks of the Gomti River in 1394, in the full memory of his cousin Juna Kha (Mo. Binu Tughlaq), Yavanpur was named after the ancient sage Yamadagni who later converted to Jaunpur, which was renovated by Firoz Shah Tughlaq had. The policy is important for rural development.

Hindi: प्रस्तुत शोध अध्ययन क्षेत्र " जौनपुर जनपद में ग्राम्य विकास गतिकी: एक भौगोलिक अध्ययन "के अन्तर्गत औद्योगिक विकास का ग्राम्य प्रतिरूप तथा समन्वित ग्राम्य विकास हेतु नियोजन का अध्ययन है। वर्तमान समय में भारतीय ग्राम्य क्षेत्र में सामाजिक, आर्थिक, राजनैतिक विकास के लिए ग्राम्य कृषि, ग्राम्य उद्योग, व्यापार रोजगार ग्राम्य विकास का संसाधन है। भारत गॉवों का देश है अतः ग्राम्यों के विकास के लिए लघु एवं कुटीर औद्योगिक विकास का ग्राम्य विकास हेतु समन्वित नियोजन की अति आवश्यकता है। " अतीत समय से जौनपुर जनपद गौरवमयी बिन्दुस्पर्शी सल्तनत होने के शिखर पर हमारे सामने है। इतिहासकार अफ्रीक के अनुसार

(C) 2020 The Author(s). This is an open access article distributed under the terms of the Creative Commons Attribution License, which permits unrestricted use, distribution, and reproduction in any medium, provided the original author and source are credited. 
सत्य नहीं है। जौनपुर नगर प्राचीन काल से ही बसा बसाया था और इसे एक प्राचीन हिन्दू राज्य की राजधानी होने का गौरव प्राप्त था। जौनपुर का प्राचीन नगर का नाम जवनपुर था। फिरोजशाह तुगलक अपने चचेरे भाई जूना खा ( मो० बिनु तुगलक) की पूर्ण स्मृति में गोमती नदी के तट पर जौनपुर नगर की नींव 1394 रखी थी, प्राचीन ऋषि यमदग्नि के नाम पर यवनपुर रखा गया था जो आगे चलकर जौनपुर में परिवर्तित हो गया जिसका जीर्णोद्धार फिरोजशाह तुगलक ने किया था ।[1] आधुनिक समय में ग्रामीण विकास के लिए ग्राम्योद्योग एवं कृषि विकास के संसाधनों का विकास करके ग्राम्य क्षेत्रों में लोगों को शिक्षा के द्वारा समग्र रोजगार का प्रशिक्षण तकनीकी कौशल के माध्यम से ग्रामीण रोजगार उपलब्ध कराकर सम्पूर्ण ग्राम विकास हेतु समन्वित नियोजन की नीति ग्राम्य विकास के लिए महत्वपूर्ण है।

Keywords: जौनपुर; जनपद; विकास

\section{1. प्रस्तावना}

शोध अध्ययन क्षेत्र जौनपुर जनपद पूर्वी उत्तर प्रदेश राज्य के पूर्वांचल में बसा एक घना जनपद है। जो वाराणसी मण्डल के उत्तरी भाग में $25^{\circ} 24^{\prime}$ से $26^{\circ} 12^{\prime}$ उत्तरी अक्षांश तथा $82^{\circ} 7^{\prime}$ से $83^{\circ} 5^{\prime}$ पूर्वी देशान्तर के मध्य भाग में स्थित है। इसकी पश्चिमी सीमा प्रतापगढ़, इलाहाबाद जनपद पूर्वी सीमा गाजीपुर आजमगढ़, उत्तरी सीमा सुल्तानपुर, दक्षिणी सीमा पर वाराणसी जनपदों द्वारा निर्मित है। इस प्रकार अध्ययन क्षेत्र में 6 तहसीलें तथा 21 विकासखण्डों में विभाजित है। अध्ययन क्षेत्र जौनपुर जनपद का 47 वर्ग किमी नगरीय क्षेत्र तथा 3998 वर्ग किमी० तथा कुल क्षेत्रफल 4038 किमी० क्षेत्र से युक्त है। 2011 की जनगणना के अनुसार कुल जनसंख्या 4494204 है जिसमें ग्राम्य क्षेत्र में जनसंख्या 4147624 तथा नगरीय क्षेत्रों में 346580 जनसंख्या है। जनसंख्या घनत्व 1113 व्यक्ति प्रति वर्ग किमी० है। जनसंख्या वृद्धि 14.89 प्रतिशत है। लिंगानुपात 1000/1021 महिलाएँ है। इस प्रकार शोधार्थिनी द्वारा अध्ययन क्षेत्र में कारखाना अधिनियम 1948 के अन्तर्गत 2014-15 कार्यरत कारखानों की 3526 है।

\section{2. जनपद जौनपुर में विभित्र संस्थानों के अधीन औद्योगिक इकाइयों की संख्या}

अध्ययन क्षेत्र जनपद जौनपुर में औद्योगिक इकाइयों की संख्या के द्वारा उद्योगों के विकास की जानकारी प्राप्त होती है। " औद्योगिक प्रदेश वह क्षेत्र होता है जहाँ पर उद्योगों का संकेन्द्रण होता है तथा अन्य कार्यो की अपेक्षा औद्योगिक क्रियाएँ प्रमुख होती है। किसी स्थान विशेष पर उद्योगों के संकेन्द्रण मात्र से ही देश औद्योगिक प्रदेश नहीं हो जाता है। इसके लिए उद्योगों के विभित्र संस्थानों की श्रृंखलाबद्धता एवं परस्पर सम्बद्धता परमावश्यक है। " किसी क्षेत्र में औद्योगिक भूद्य के विकास के लिए कारखानों की संख्या, कर्मचारियो की संख्या, उत्पादन में लगे व्यक्तियों की संख्या, उद्योगों में लगे कुल श्रमिकों की कुल जनसंख्या का अनुपात, ऊर्जा की मात्रा, कुल औद्योगिक उत्पादन, मूल्य सम्बन्धी आँकड़े, उत्पादन प्रक्रिया जत्रू मूल्य वृद्धि के आधार पर औद्योगिक प्रदेशों का सीमांकन किया जा सकता है।

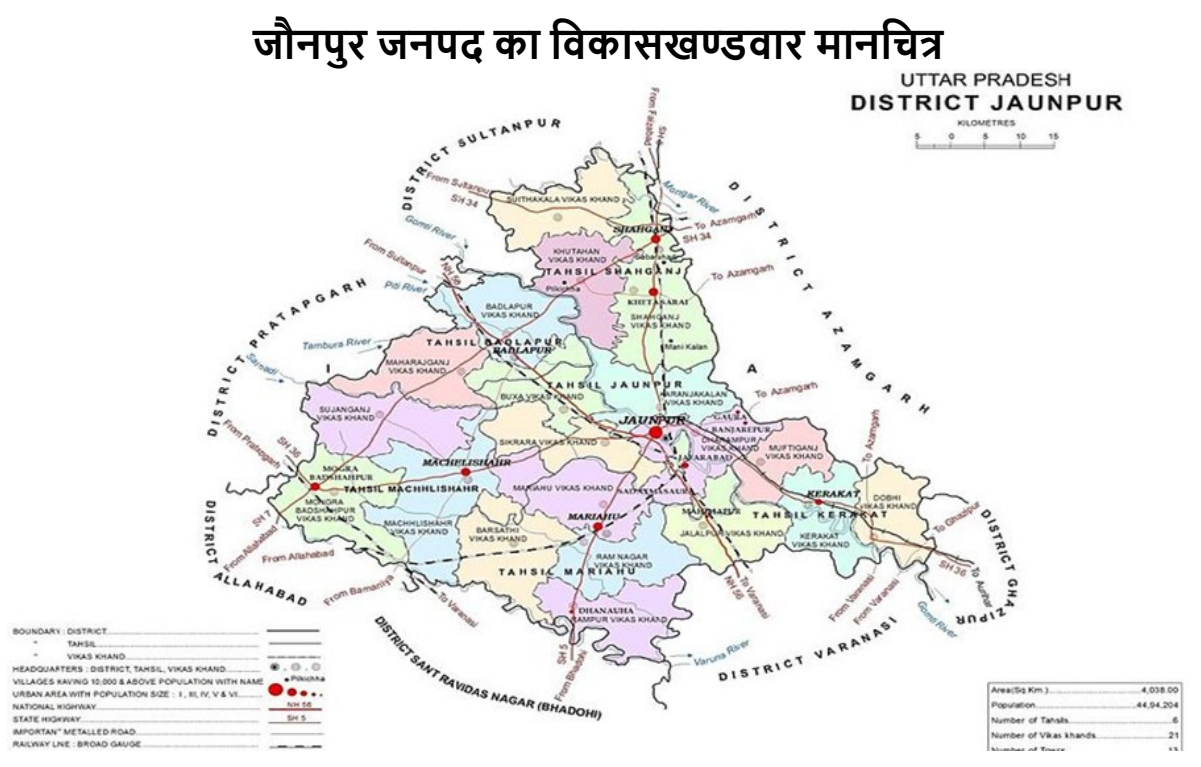


जौनपुर जनपद में औद्योगिक विकास का ग्राम्य प्रतिरूप तथा समन्वित ग्राम्य विकास हेतु नियोजन

जौनपुर जनपद में विभित्र प्रकार के संस्थानों के अधीन कार्यशील ग्रामीण एवं लघु औद्योगिक इकाइयों की संख्या 2017-18

\begin{tabular}{|c|c|c|c|c|c|c|c|}
\hline \multirow{2}{*}{$\begin{array}{l}\text { क0 } \\
\text { सं० }\end{array}$} & \multirow[t]{2}{*}{ संस्था का नाम } & \multicolumn{6}{|c|}{ चालित } \\
\hline & & $\begin{array}{l}\text { पंचायत } \\
\text { द्वारा }\end{array}$ & $\begin{array}{l}\text { क्षेत्र } \\
\text { समिति } \\
\text { द्वारा } \\
\end{array}$ & $\begin{array}{l}\text { औद्योगिक } \\
\text { सहकारी } \\
\text { समिति द्वारा }\end{array}$ & $\begin{array}{l}\text { पंजीकृत } \\
\text { संस्था } \\
\text { द्वारा }\end{array}$ & $\begin{array}{l}\text { व्यक्गित } \\
\text { उद्योगपतियों } \\
\text { द्वारा }\end{array}$ & $\begin{array}{l}\text { कुल } \\
\text { योग }\end{array}$ \\
\hline 1 & खादी उद्योग & 0 & 0 & 0 & 4 & 0 & 4 \\
\hline 2 & $\begin{array}{l}\text { खादी ग्रामोद्योग द्वारा } \\
\text { परिवर्तित ग्रामीण } \\
\text { उद्योग }\end{array}$ & 0 & 0 & 11 & 5 & 1749 & 1765 \\
\hline 3 & लघु उद्योग इकाइयॉ & & & & & & \\
\hline 3.1 & इंजीनियरिंग & 0 & 0 & 0 & 0 & 37 & 37 \\
\hline 3.2 & रासायनिक & 0 & 0 & 0 & 0 & 8 & 8 \\
\hline 3.3 & विधायन & 0 & 0 & 0 & 0 & 0 & 0 \\
\hline 3.4 & हथकरघा & 0 & 0 & 0 & 0 & 0 & 0 \\
\hline 3.5 & रेशम & 0 & 0 & 0 & 0 & 0 & 0 \\
\hline 3.6 & नारियल की जटा & 0 & 0 & 0 & 0 & 0 & 0 \\
\hline 3.7 & हस्तशिल्प & 0 & 0 & 0 & 0 & 0 & 0 \\
\hline 3.8 & अन्य & 0 & 0 & 11 & 0 & 778 & 778 \\
\hline 4.0 & योग $(1+2)$ & 0 & 0 & 11 & 9 & 1749 & 1769 \\
\hline 5.0 & $\begin{array}{l}\text { योग } 3.1 \text { से } 3.8 \\
\text { योग ग्रामीण एवं लघु } \\
\text { उद्योग }(4+5)\end{array}$ & $\begin{array}{l}0 \\
0\end{array}$ & $\begin{array}{l}0 \\
0\end{array}$ & $\begin{array}{l}11 \\
22\end{array}$ & $\begin{array}{l}0 \\
9\end{array}$ & $\begin{array}{l}823 \\
2572\end{array}$ & $\begin{array}{l}834 \\
2603\end{array}$ \\
\hline 6 & $\begin{array}{l}\text { कार्यरत व्यक्तियों की } \\
\text { संख्या }(1+2)\end{array}$ & 0 & 0 & 149 & 359 & 5948 & 6456 \\
\hline 7 & $\begin{array}{l}\text { लघु उद्योग इकाइयों } \\
\text { में कार्यरत व्यक्ति } 3.1 \\
\text { से } 3.8\end{array}$ & 0 & 0 & 0 & 0 & 2612 & 2612 \\
\hline 8 & $\begin{array}{l}\text { ग्रामीण एवं लघु } \\
\text { उद्योग इकाइयों में } \\
\text { कार्यरत व्यक्तियों की } \\
\text { संख्या }(6+7)\end{array}$ & 0 & 0 & 149 & 359 & 8560 & 9068 \\
\hline
\end{tabular}

स्रोत:- जिला खादी एवं ग्रामोद्योग अधिकारी जौनपुर 2017-18 तालिका संख्या 35

अध्ययन क्षेत्र में लघु औद्योगिक इकाइयों की संख्या तथा कार्यशीलता ग्रामीण व्यक्तियों की संख्या के आधार पर विभित्र संस्थाओं में अद्योगों के विकास का अध्ययन किया गया है। इस प्रकार पंचायत द्वारा, क्षेत्र समिति द्वारा, औद्योगिक समिति द्वारा, पंजीकृत संस्थाओं द्वारा, व्यक्तिगत उद्योगपतियों द्वारा विभाजित किया गया है। अध्ययन क्षेत्र जनपद जौनपुर में कुल संस्थाओं द्वारा उद्योगों का निर्माण 2017-18 के अन्तर्गत 9068 है। पंचायत द्वारा औद्योगिक इकाइयों की संख्या 0 है तथा क्षेत्र समिति द्वारा लघु औद्योगिक इकाइयों की संख्या 0 है। सहकारी औद्योगिक समिकत द्वारा 215 है। पंजीकृत संस्थाओं के द्वारा 386 हे। व्यक्तिगत उद्योगपतियों के द्वारा 8560 हैं। इस प्रकार जनपद में विभित्र संस्थानों के द्वारा औद्योगिक इकाइयों की संख्या तथा कार्यशील ग्रामीण इकाइयों की संख्या विभित्र औद्योगिक संस्थाओं में जैसे खादी उद्योग 4, खादी ग्रामोद्योग 1765 , लघु उद्योग इकाइया, इंजीनियरिंग 37 , रासायनिक 8 , विधायन 0, हथकरघा 0, रेशम 0, नारियल की जटा 0, हस्तशिल्प 0, अन्य 789 योग (1\$2) 1769 योग कालम (3.1 से 3.8) 834 कुल योग ग्रामीण 
2603 कार्यरत व्यक्तियों की संख्या (1\$2) 6456, लघु इकाइयों में कार्यरत व्यक्ति (3.1 से 3.8) के मध्य 2612, ग्रामीण एवं लघु उद्योगों में कार्यरत व्यक्तियों की संख्या 9068 है। इस प्रकार शोधार्थिनी द्वारा अपने शोध क्षेत्र में उद्योगों की संख्या तथा कार्यरत व्यक्तियों की संख्या का अध्ययन किया गया है।

\section{3. जौनपुर जनपद में विकासखण्डवार लघु औद्योगिक इकाइयों की संख्या तथा कार्यरत व्यक्तियों की संख्या का विश्लेषण}

शोधार्थिनी अपने शोध क्षेत्र में 2017-18 की गणना के अनुसार लघु उद्योग तथा कार्यरत व्यक्तियोंकी संख्या के आधार पर विभित्र प्रखण्डों में अध्ययन किया है।

जौनपुर जनपद में पंजीकृत कारखाने, लघु औद्योगिक इकाई, खादी ग्रामोद्योग में कार्यरत व्यक्तियों की संख्या विकासखण्डवार 2017-18

\begin{tabular}{|c|c|c|c|c|c|c|c|}
\hline \multirow[t]{2}{*}{$\begin{array}{l}\text { क0 } \\
\text { सं० }\end{array}$} & \multirow[t]{2}{*}{$\begin{array}{l}\text { विकासखण्ड } \\
\text { वर्ष 2017-18 }\end{array}$} & \multicolumn{2}{|c|}{$\begin{array}{l}\text { पंजीकृत } \\
\text { कारखाने }\end{array}$} & \multicolumn{2}{|c|}{$\begin{array}{l}\text { लघु औद्योगिक } \\
\text { इकाइयॉ }\end{array}$} & \multicolumn{2}{|c|}{$\begin{array}{l}\text { खादी ग्रामोद्योग } \\
\text { इकाइयॉ }\end{array}$} \\
\hline & & $\begin{array}{l}\text { कारखानो } \\
\text { की संख्या }\end{array}$ & $\begin{array}{l}\text { कार्यरत } \\
\text { व्यक्ति }\end{array}$ & $\begin{array}{l}\text { इकाइयों } \\
\text { की } \\
\text { संख्या }\end{array}$ & $\begin{array}{l}\text { कार्यरत } \\
\text { व्यक्ति }\end{array}$ & $\begin{array}{l}\text { इकाइयों } \\
\text { की } \\
\text { संख्या }\end{array}$ & $\begin{array}{l}\text { कार्यरत } \\
\text { व्यक्ति }\end{array}$ \\
\hline 1 & सुझ्था कला & 0 & 0 & 17 & 28 & 78 & 202 \\
\hline 2 & शाहगंज & 4 & 69 & 39 & 108 & 1008 & 397 \\
\hline 3 & खुटहन & 0 & 0 & 32 & 22 & 76 & 229 \\
\hline 4 & करंजाकला & 1 & 952 & 45 & 128 & 89 & 286 \\
\hline 5 & बदलापुर & 0 & 0 & 42 & 119 & 75 & 270 \\
\hline 6 & महाराजगंज & 0 & 0 & 31 & 79 & 70 & 212 \\
\hline 7 & बक्सा & 0 & 0 & 28 & 14 & 87 & 482 \\
\hline 8 & सुजानगंज & 0 & 0 & 15 & 18 & 80 & 270 \\
\hline 9 & मुरादाबाद शाहपुर & 12 & 598 & 45 & 130 & 89 & 295 \\
\hline 10 & मछलीशहर & 0 & 0 & 35 & 86 & 104 & 405 \\
\hline 11 & मड़ियाहूँ & 0 & 0 & 45 & 129 & 96 & 285 \\
\hline 12 & बरसठी & 0 & 0 & 34 & 89 & 79 & 232 \\
\hline 13 & सिकरारा & 0 & 0 & 28 & 20 & 61 & 333 \\
\hline 14 & धर्मापुर & 0 & 0 & 20 & 23 & 67 & 189 \\
\hline 15 & रामनगर & 0 & 0 & 16 & 25 & 80 & 243 \\
\hline 16 & रामपुर & 2 & 22 & 23 & 87 & 66 & 174 \\
\hline 17 & मुप्तीगंज & 0 & 0 & 32 & 65 & 69 & 185 \\
\hline 18 & जलालपुर & 2 & 39 & 14 & 18 & 78 & 283 \\
\hline 19 & केराकत & 2 & 227 & 30 & 6 & 76 & 190 \\
\hline 20 & डोभी & 1 & 73 & 13 & 15 & 70 & 196 \\
\hline 21 & सिरकोनी & 0 & 0 & 46 & 118 & 106 & 485 \\
\hline & योग ग्रामीण & 24 & 1980 & 640 & 1327 & 1704 & 5843 \\
\hline & योग नगरीय & 5 & 55 & 153 & 475 & 45 & 190 \\
\hline & योग जनपद & 29 & 2035 & 793 & 1802 & 1749 & 6033 \\
\hline
\end{tabular}

स्रोतः-जिला खादी एवं ग्रामोद्योग अधिकारी जौनपुर 207-18 तालिका सं0 37 
जनपद जौनपुर में पंजीकृत कारखाने, लघु औद्योगिक इकाइया, खादी ग्रामोद्योग इकाइया तथा उनमें कार्यरत व्यक्तियों की संख्या के अन्तर्गत 2017-18 विकासखण्ड वार अध्ययन किया गया है। जिसमें पंजीकृत कारखानों की संख्या ग्रामीण क्षेत्रों मे 24 तथा नगरीय क्षेत्रों में 5 है तथा कार्यरत व्यक्तियों की 1980 तथा तथा नगरीय क्षेत्रों में 55 है। लघु औद्योगिक इकाइयों की संख्या 793 जिसमें ग्रामीण क्षेत्रों में 640 तथा नगरीय क्षेत्रों में 153 है तथा कार्यरत व्यक्तियों की कुल जनपद योग 1802 जिसमें ग्रामीण क्षेत्रों में 1327 तथा नगरीय क्षेत्रों में 475 है। खादी ग्रामोद्योग इकाइयों की संख्या 1749 है जिसमें ग्रामीण क्षेत्रों में 1704 तथा नगरीय क्षेत्रों में 45 है तथा कार्यरत व्यक्तियों की संख्या 6033 है। ग्रामीण क्षेत्रों में 5843 तथा नगरीय क्षेत्रों में 190 है , इस प्रकार शोधार्थिनी अपने अध्ययन क्षेत्र जनपद जौनपुर में विकासखण्डवार पंजीकृत पंजीकृत कारखाने की संख्या के उच्चतम प्रखण्ड मुगराबादशाहपुर 12 , शाहगंज 4 , रामपुर 2 , केराकत 2,जलालपुर 2, डोभी 1, करंजाकला 1 तथा अन्य प्रखण्डों में 0 हैं कारखानों में कार्यरत व्यक्तियों की संख्या उच्चतम स्तर के प्रखण्ड करंजाकला 952, मुगराबादशाहपुर 598 , केराकत 227, डोभी 73 , शाहगंज 69 , रामपुर 22, जलालपुर 39, तथा अन्य प्रखण्डों में 0 है। लघु औद्योगिक इकाइयों की संख्या के उच्चतम प्रखण्ड सिरकोनी 46, करंजाकला 45 , मुगराबादशाहपुर 45 , मड़ियाहू 45 , शाहगंज 39 के प्रखण्ड हैं तथा न्यूनतम स्तर के प्रखण्ड डोभी 13 , जलालपुर 14 , रामनगर 16 , सुजानगंज 15 , सूइयाकला 17 , न्यूनतम स्तर के प्रखण्ड है तथा लघु इकाइयों में कार्यरत व्यक्तियों की संख्या के उच्चतम स्तर के प्रखण्ड-मुगराबादशाहपुर 130, मड़ियाहू 129, करंजाकला 128, सिरकोनी 118 प्रखण्ड है तथा न्यूनतम स्तर पर प्रखण्डों की कार्यरत व्यक्तियों की संख्या प्रखण्ड केराकत 6, बक्सा 14 , डोभी 15 , सुजानगंज 18 , जलालपुर 18 , न्यूनतम स्तर के प्रखण्ड है। खादी ग्रामोद्योग इकाइयों की संख्या के उच्चतम स्तर के प्रखण्ड शाहगंज 108, सिरकोनी 106, मछलीशहर 104 , मड़ियाहु 96, करंजाकला 89, के प्रखण्ड है तथा न्यूनतम स्तर के प्रखण्ड-सिकरारा 61 , रामपुर 66 , धर्मापुर 67 , महाराजगंज 70 न्यूनतम स्तर के प्रखण्ड है। खादी ग्रामोद्योग में कार्यरत व्यक्तियों की संख्या उच्चतम स्तर के प्रखण्ड सिरकोनी 333, उच्च स्तर के प्रखण्ड है तथा न्यूनतम स्तर के प्रखण्ड रामपुर है और सभी प्रखण्डों को मध्यम स्तर मान लिया गया है । शोधार्थिनी अपने शोध क्षेत्र में लघु औद्योगिक कारखानों तथा कार्यरत व्यक्तियों की संख्या के आधार पर अध्ययन करके तुलनात्मक विश्लेषण किया गया है।

\section{4. जनपद जौनपुर में औद्योगिक ग्राम्य विकास का प्रतिरूप}

शोध अध्ययन क्षेत्र जौनपुर जनपद में ग्राम्य विकास प्रतिरूप के लिए ग्राम स्तर पर औद्योगिक इकाइयों की स्थापना ग्रामीण कच्चे माल एवं उपभोग के अन्तर्गत विकास किया जा सकता है। इस सम्बन्ध में " भारत सरकार गरीबों और ग्रामवासियों के लिए पूरी तरह समर्पित है जन शक्ति एवं जन भागीदारी के माध्यम से हमारा उद्देश्य गॉवो में लोगों के जीवन स्तर और लोक सेवाओं की गुणवत्ता में सुधार लाना भारत सरकार राष्ट्रपिता महात्मागांधी के ग्राम्य स्वरोजगार की परिकल्पना को साकार करने की दिशा में लगातार काम कर रही है। मेरा विश्वास दिलाना चाहना हू कि हमारे गॉव के विकास के लिए गॉव के लोगों के सशक्तिकरण के लिए गॉव की समस्याओं से मुक्ति दिलाने के लिए आज जो भी संकल्प करेगें उन्हे पूरा करने में भारत सरकार पूर्ण प्रतिबद्धता के साथ हमेशा आपके साथ रहेगी और समग्र ग्राम्य का विकास होगा।" नरेन्द्र मोदी जी, [5] "ग्राम्य विकास के प्रतिनिधियों एवं कर्मचारियों के प्रशिक्षण तकनीकी समर्थन और मानव संसाधन उपलब्ध कराने के लिए राष्ट्रीय ग्राम्य स्वराज अभियान योजना प्रारम्भ की गयी है। इस योजना के तहत गरीबी के हितैषी कल्याण के लिए प्रधानमंत्री जनधन योजना, सुरक्षा बीमा योजना, जीवन ज्योति, बीमा योजना, सौभाग्य योजना, उज्जवला योजना, उजाला योजना, आवास योजना, ग्राम सड़क योजना, दीनदयाल अन्त्योदय, राष्ट्रीय ग्रामीण आजीविका, ग्रामीण कौशल कार्यक्रम कार्यान्वित कर रही है। इसके साथ ग्राम्य विकास के लिए ग्राम पंचायत पूर्व योजना, पारदर्शी प्रणाली, आधुनिक तकनीक का उपयोग सामुदायिक भागीदारी आन्तरिक सामाजिक मूल्यांकन, नवाचारों का उपयोग रोजगार के अवसरों का सृजन, स्वच्छता, सामाजिकता, आत्मनिर्भरता, आत्म समृद्ध राष्ट्र समृद्ध योजनाओं के माध्यम से ग्रामीण विकास किया जा रहा है। " [6]

\section{5. समन्वित ग्राम्य विकास हेतु नियोजन}

अध्ययन क्षेत्र जनपद जौनपुर सहित ग्राम्य विकास हेतु नियोजन की आवश्यकता तब महत्वपूर्ण मानी गयी जब लोगों को ग्राम्य विकास से ही मनुष्य की सम्पूर्ण क्रियाकलाप को आधार प्रदान किया गया जैसे-कृषि कार्य, पशुपालन, आवास, भोजन के लिए अत्र भण्डार आर्थिक सामाजिक, राजैैतिक क्रियाओं का ग्राम्य विकास से ही ग्रामीण अर्थव्यवस्था को आधार प्रदान किया जाता है। " भारत में ग्राम्य विकास को आधार प्रदान करने के लिए ग्राम पंचायती राज की अवधारणा 2 अक्टूबर 1959 ई0 पू०, जवाहर लाल नेहरू द्वारा ग्राम्य विकास के योजनाएँ बनायी गयी। 1963 के सम्पूर्ण भारत में ग्राम विकास के लागू की गयी। 1993 में 73 वे संविधान अधिनियम के अन्तर्गत पंचायती राज्य व्यवस्था के अन्तर्गत सम्पूर्ण ग्राम्य विकास योजना के माध्यम से ग्राम पंचायत विकासखण्ड , पंचायत, जिला पंचायत के द्वारा समग्र विकास आधार प्रदान किया गया है। " [7] 


\section{डॉ. अनामिका सिंह, सुजीता देवी}

"अध्ययन क्षेत्र सहित सभी जनपदों में सांसद आदर्श ग्राम योजना के अन्तर्गत प्रत्येक जनपदों में एक गॉव का परिवर्तन के अन्तर्गत सम्पूर्ण जनपद के ग्राम्यों के विकास की योजना भारत सरकार माननीय सांसद के नेतृत्व में ग्राम पंचायत ने कई जागरूकता शिविरों का आयोजन करके ग्रामीणें के व्यवहार में सकारात्मक बदलाव देखा गया। आदर्श ग्राम योजना अन्तर्गत स्कूल का उत्रयन, पंचायत घर का निर्माण वृक्षारोपण, स्वास्थ्य कार्ड, आवास निर्माण, जल संचय ग्रामीणों के स्वरोजगार कार्यक्रम, आर्थिक रोजगार, सामाजिक कल्याण आदि योजना ग्राम्य विकास के लिए महत्वपूर्ण है। "[8] शोधार्थिनी अपने शोध क्षेत्र में प्रधानमंत्री ग्राम विकास योजना के अन्तर्गत " नियोजन समस्याओं के तार्किक समाधान और साधनों एवं साध्यों को समन्वित करने का प्रयास के आर्थिक प्रगति के साथ ही सामाजिक सांस्कृतिक, राजनैतिक आदि उद्देश्यों की प्राप्ति ग्रामीण विकास से ही सम्भव है।

\section{6. निष्कर्ष एवं सुझाव}

शोध अध्ययन क्षेत्र जनपद जौनपुर में औद्योगिक विकास का ग्राम्य विकास प्रतिरूप का समन्वित ग्राम्य विकास हेतु नियोजन का विश्लेषण किया गया है। शोधार्थिनी ने ग्राम्य विकास लघु औद्योगिक इकाइयों एवं कार्यरत श्रमिकों की प्रगति रोजगार एवं विकास के साथ ग्रामीण क्षेत्रों में समन्वित विकास की योजना की व्याख्या की गयी है। जिससे सम्पूर्ण अध्ययन के विकास के लिए विभित्र पहलुओं के अन्तर्गत ग्राम्य का विकास करना सम्भव है। ग्राम्य विकास के लिए प्रधानमंत्री सड़क योजना, कृषि विकास योजना, आवास निर्माण योजना, सौभाग्य ( विद्युत्तीकरण) योजना , स्कूल चलो योजना, स्वास्थ्य बीमा एवं सुरक्षा योजना, लघु सिंचाई योजना, पशुपालन योजना, मछली पालन, बैंक ऋण योजना, पेयजल सुरक्षा योजना, वृक्षारोपण योजना, जैविक कृषि योजना, पर्यावरण संरक्षण योजना, जैविक खाद योजना, कौशल विकास मिशन योजना, कृषि प्रशिक्षण योजना, बीज उर्वरक योजना, सामाजिक कल्याण योजना, आदर्श ग्राम्य विकास योजना, मानव कल्याण एवं प्रशासनिक योजना, अन्त्योदय योजना, मनरेगा योजना आदि।

\section{SOURCES OF FUNDING}

None.

\section{CONFLICT OF INTEREST}

None.

\section{ACKNOWLEDGMENT}

None.

\section{REFERENCES}

[1] डॉ. सत्यनारायण दुबे, जौनपुर का गौरवशाली इतिहास 2013, शारदा पुस्तक भवन इलाहाबाद, पृष्ठ सं0 42

[2] डॉ. चतुर्भुज मामोरिया डॉ. एम एस सिसौदिया: आर्थिक भूगोल, 2009, साहित्य पब्लिकेशन हाउस आगरा पृष्ठ सं0 312

[3] जनपद सांख्यिकीय पत्रिका जौनपुर 2017-18, तालिका संख्या 35

[4] जनपद सांख्यिकीय पत्रिका जौनपुर जनपद 2017-18, तालिका संख्या 37

[5] ग्रामोदय संकल्प पत्रिका अक्टूबर मई 2018, पृष्ठ सं 2

[6] ग्रामोदय संकल्प पत्रिका नई दिल्ली अक्टूबर-मई 2018, पृष्ठ सं0 5

[7] डॉ. एस. डी. मौर्य: अधिवास भूगोल 2017, शारदा पुस्तक भवन इलाहाबाद पृष्ठ सं0 118

[8] ग्रामोदय संकल्प त्रैमासिक पत्रिका, अक्टूबर-मई 2018, पृष्ठ सं० 18, 19

[9] रोजगार समाचार पत्र, लेख इन्टरनेट आदि। 